\title{
A Study on E-C Subtitle Translation of the NetEase Open Educational Resources from the Perspective of Skopos Theory
}

\author{
A Case Study of the Harvard Open Course Postive Psychology
}

\author{
Jing Guo \\ College of Foreign Language \\ Wuhan Universtiy of Science and Technology \\ Wuhan, China
}

\begin{abstract}
As a new type of curriculum, the Network Open Educational Resources (NOER) are becoming increasingly popular with the development of network technology. And it is also an important access to self-learning for domestic learners. Due to the high quality of NORE and the great expectation from the target audience, the translation of its subtitles is of great importance. It is a burning issue for the translator of NOER to figure out how to meet the target audiences' need. Skopos theory is a translation theory proposed by a translation theorist, Hans J Vermeer. According to it, the prime principle that determines the translation process is the purpose (skopos) of the overall translational action. In other words, the purpose of target text determines the translation strategies and methods. There are many investigations on skopos theory both at home and abroad, whereas, few researches have been made on the practical use of skopos theory on STNOER. To solve the problems mentioned above, this paper adopts research approaches including literature reading, sample analysis and induction. From the perspective of skopos theory, this paper analyzes the characteristics and demands of target audience of NOER. Through a case study of the Harvard Open Courses Positive Psychology, this paper proposes three translation strategies according to the purpose of the target text: (1) for professors, more technical and academic terms should be adopted and the instructors' teaching style embodied in the translation; (2)in terms of students, the sophisticated principles in the course should be illustrated in a simple way and some creative words can be added to the target text properly; (3)as for self-learners, translators should highlight the rhetorical function of the source text and deliver messages directly.
\end{abstract}

Keywords-NetEase open educational resources; skopos theory; subtitle translation; positive psychology

\section{INTRODUCTION}

With the rapid development of digital television and network technique, the network open educational resources, which are established for the purpose of sharing network resource, are gaining great popularity. The network open educational courses have provided a great chance for domestic learners to learn from world's high-quality educational resources [1]. As a new type of class, the NOER has enjoyed high concern since they have been released. However, due to language obstacles, most of Chinese audience or learners need subtitle translations to understand the video's contents. With their own distinct characteristics, the target audiences of STNOER demand higher for ST. The E-C subtitle translation of NOER not only contains immense knowledge, but also assumes great responsibility to deliver instructor's ideology. What's more, the target audiences of E-C subtitle translations are mostly learners with a certain degree of educational backgrounds [2].

As mentioned above, this paper analyzes the characteristics of the target audience of target text. On the basis of those characteristics, the paper proposed some translation strategies to E-C subtitle translation of NOER, hoping to provide some suggestions for other translators.

\section{SKOPOS THEORY}

Skopos is a Greek word for 'purpose' and was introduced into translation theory in the 1970s by Hans J Vermeer as a technical term for the purpose of a translation. According to skopostheorie (the theory that applies the notion of skopos to translation), the prime principle determining any translation process is the purpose (skopos) of the overall translational action. Skopos theory is a theoretical basis of translation; it is used to guide the translation practice of advertisement, movie subtitle, tourist materials, news English and other kinds of text.

Guided by Human Behavior Theory, Skopos theory puts the translation into Human Behavior Theory category. The skopos theorists think that "translation is a cross-cultural communicative activity in the role of the translator with clear purpose and intention and is based on the original text. And they also think that the nature of skopos theory is for communication" [3]. In brief, skopos theory comprises the idea that translating and interpreting should primarily take the function of both the source and target text into consideration 


\section{THREE PRINCIPLES OF SKOPOS THEORY}

The skopos theory consists of three rules, which are skopos rule, coherence rule and loyalty rule.

\section{A. Skopos Rule}

The skopos theory takes the skopos rule as the primary rule that all translation work should obey. The purpose that a translate behavior wants to reach determines the whole process of translation. In another word, "the end justified the means". But for one translation behavior, there can be many purposes, we can distinguish between three possible kinds of purpose in the field of translation: the general purpose of the translator in the translation process (perhaps ' to earn a living') the communicative purpose of the target text in the target situation(perhaps 'to instruct the reader') and the purpose of a particular translation strategy or procedure( for example,' to translate literally in order to show the structural particularities of the source language') however, in most of the cases, purpose refer to the communicative purpose of the target text, therefore, translators should understand its determined purpose in the given situation, and choose the proper translation strategy according to this purpose. [4]

\section{B. Coherence Rule}

The coherence rule means that the target text must meet the intra-textual coherence standard. The target text should be readable and acceptable. The target text should be accepted by receivers and be meaningful in communicative situation. Fidelity rule means that source text and target text should have inter-textual coherence. In other systems we should be loyal to source text and determine the degree and form by the purpose and the translator's understanding of target text.

\section{Loyalty Rule}

The loyalty rule was proposed by Nord (2001). She found two disadvantages of skopos theory: first is that people from different culture background have their own standard of a good-text. Another problem is that if the communicative purpose of target-text is contrary to original author's intention, we will obey skopos rule and go against fidelity rule. Therefore, Nord proposed loyalty rule to eliminate culture difference and relationship between participates in translate behavior. In Nord's opinion, translators have moral responsibility for target audience, they need to explain to text-receivers what they have done and why they do so. This is one aspect of loyalty rule; the other aspect is that translators should be loyal to original author. Translators should respect the original author, coordinate target text with author's intention [5]. Therefore, loyalty rule mainly focuses on the relationship between participates like translator and original author, client, target-text receivers.

\section{TARGET AUdiENCE OF SUbtitle TRANSLATION OF THE NETEASE OPEN EDUCATIONAL RESOURCES}

Skopos theory perceives translation as an activity with an aim or purpose and with the intended addressee or audience of the translation. To translate means to produce a target text in a target setting for a target purpose and target addressees in target circumstances [6]. In skopos theory, the status of the source text is lower than it is in equivalence-based theories of translation. As for network open educational resources, target audiences' need is of most importance. According to MIT's research on target audience of NOER, the audience can be divided into three groups: professors, students and self-learners. Knowing what they want can help translator to choose proper translation strategies. In November 1st, 2011, the NetEase officially launched the "global elite online open educational courses", which is the first protal that put forward the network open educational courses.

\section{A. For Professors}

A professor is an expert in arts or sciences, or a teacher of the highest rank. Professors are qualified experts who can manage the teaching, research and publications in their departments; conduct lectures and seminars in their specialties; perform advanced research in their fields and adopt instructional technology to teach campus-based or online courses.

1) Teaching Skills and Concepts: As a new type of class, the NetEase open educational resources have been welcomed by professors. Professors are a group of people who have a certain degree of professional knowledge and English communication ability. Professors' academic qualifications are mostly above bachelor's degree, and some are even above master's degree nowadays. Though professors have a high qualification in their major field, some are still very poor in English and still need the help of subtitle translation. In professor's daily work, they have accumulated a lot of work experience and they are getting used to their own route in class [7]. However, the appearance of network open educational resource opened a new world for professors, instructors from those worldfamous universities which can introduce many new teaching skills and concepts to the class. That is one of the reasons why many professors choose it. Compared with domestic classes, those foreign courses have a freer atmosphere in their class, and the students' enthusiasm to participate in class is much higher than our students'. As a Chinese saying, 'Experts grasp the essence, while the amateurs notice the surface', when a professor watches an open educational course, he(she) cares more about the whole class organization and how the instructor guides the students and students' feedback. Those are the things that professors concentrate on. They want to learn more teaching skills to improve their teaching ability. And they are also very glad to accept new concepts in teaching. So for professors, learning teaching skills and concepts is the first thing they want to get from the NOER.

2) Scholars' Personal Characteristics: Another reason why professors are attracted by the NetEase online open educational courses is that they can benefit from the NetEase's abundant teaching resources. The NetEase Open Educational Courses have collected excellent courses of 
world-famous universities like Harvard, Yale, Oxford, Stanford, MIT. Similarly, many excellent instructors are also included in these courses. Scholars of those famous universities also attract many audiences. In general, those famous scholars are the leading authority of a specific subject. Their way of thinking and their analysis on research object are usually very unique. Their teaching methods and concepts are often marked with their personal characteristics [8]. Professors with professional knowledge backgrounds often adore such scholars. They are attracted by those scholars' personal characters and they want to know more about the scholars. With limited domestic resources, NOER is a good way for professors to get what they want.

\section{B. For Students}

Students are another group of network open educational resources' target audience. This group also has its own characteristics. They have a basic knowledge reserve and have spare time to spend on study, they are very creative and are curious about new things [9] When they use network open educational resources, they often want to learn two kinds of things. One is disciplinary knowledge while the other is updated knowledge.

1) Disciplinary Knowledge: As a student, especially a student at college, learning disciplinary knowledge well is a basic task. However, most students couldn't keep up with this standard, they may not digest what their teacher have taught in class in time, so after class they need to spend more time on their major subjects. English majors may use network open educational resources to practice their listening skill. Medical major students may use these courses to learn more about biology and chemistry. A common problem for different major students is that they couldn't catch up with the speed of teacher's speaking or they couldn't understand some academic terms, though they have passed the CET4 or CET6, for those students, the subtitle translation is still very necessary.

2) Updated Knowledge: Apart from disciplinary knowledge, students are likely to watch some updated videos in their spare time. The rich resources of network open educational course endow a better place for students to broaden their horizon. Boys always concentrate more on subjects like military science, computer science and technology, politics, economics, geography science, etc. Girls are keen on some humanities and social science subject, such as psychology, speech, language, management, etc. As a group of young people, students are often very creative and curious about new things. Another good character is that they are willing to accept new things [10]. Those resources help them to know what' s going on in the world and accept new things appearing in the video.

\section{For Self-Learners}

In our traditional concept, teachers and students are the two major part of the class. In this paper, there is a third group, self-learners. People who learned these courses automatically and do not belong to professor or students group can be classified into this group. The character of selflearners is that their knowledge backgrounds vary widely [11]. Self-learners can be a white-collar worker who graduates from a very good university and has a good master of English. And he can also be a blue-collar worker who is much more familiar with technology than with English. The characteristics of this group should also be taken into consideration.

1) Personal Interests: People often say that interest is the best teacher, which is quite right when self-learners are involved. Self-learners dabble in all kinds of subjects listed on the internet. A surgeon may watch an episode of speech at weekend. A middle-aged man may watch an episode of politics after work. From this point, there is a great span between self-learners in knowledge background and many of them know nothing about the subject they are learning [12]. To satisfy all the audience of online open educational resources, translators should take poor education background learners as the standard and try to simplify the sophisticated principles and make it more interesting to learn.

2) Job Demand: Apart from self-learners' personal interests, the outside world pressure is one of reasons pushing them to learn. The outside world pressure can be seen as self-learners' job demand in a narrow sense, because pressures from their work force them to learn. When we mentioned target audience of network open educational resources, it can be an individual person, but sometimes it can also be an organization, media, enterprise, etc [13]. An accountant may watch the intermediate microeconomics from UCB to get another certificate and the boss of an enterprise may watch Positive Psychology to encourage his staff to work in a happy mood.

Above all, the target audience of online open educational resource can be divided into three groups in general and each group has its own characteristics. Therefore, their demands for E-C subtitle translation are different. The translators should try to take the audience's characteristics into consideration and adapt their version to the target audiences' demands.

\section{RECOMMENDABLE STRATEGIES FOR THE E-C SubTITLE TRANSLATION OF THE HARVARD OPEN COURSES POSITIVE PSYCHOLOGY}

Scholars have made a lot of researches on E-C subtitle translation of online open educational resources before. On the basis of their researches, they also provided many translation strategies such as amplification and omission. However, those strategies are proposed from the perspective of the source text or the target text, the target audience's need is seldom taken into consideration. After analyzing the target audience's characteristics, this paper, under the guidance of the skopos theory, proposed some translation strategies on E-C subtitle translation through a case study of the Harvard Open Course Positive Psychology. 


\section{A. Preserving Academic and Technical Terms}

The online open educational resource is a kind of curriculum whose function is to disseminate knowledge, so the requirement for its quality is higher than other kinds of subtitle translation. All the target audience uses it to learn something so the versions need to be formal and accurate [14]. Here are some versions.

In the first lesson of Positive Psychology, Tal, the teacher of this course, gives a brief introduction to Positive Psychology. Many translators may translate the last sentence of "...these things make a difference, can even make a more of difference. But not accessible to most people...” into “但是 很多人并不能接受它” or “但是很多人并不理解它”. From the literal meaning, it is not wrong. In the final version, the translator translates it like this “但是对大众来说晦澀难懂”. The key word “accessible" was translated into “䀲澀难懂”, indicating the present situation of Positive Psychology clearly and vividly.

Another sentence in this lecture, “... indeed the following study that I think confirms the importance of 'time-in' time to look inside..." in this lesson is also a good example. When you check the phrase 'time-in', you may got the explanation like “恢复比赛” or “时间在”, but in this video, 'time-in' was translated into “练习时间”, which is a technical term used in Positive Psychology. When audience like professors see this version, they will understand what the instructor means.

Using academic and technical terms is a necessary requirement for ST of NOER. In literature and the humanities course like Positive Psychology, this strategy may not be demonstrated obviously, but it is especially fit for natural science courses. When translating these courses, translators should care more about the adequacy and accuracy of those academic or technical terms.

\section{B. Adapting to Instructor's Teaching Style}

The contents of courses can attract people to learn the course, so can a good teacher. Many people come to learn the courses because of the instructor's personal charm. Instructors with good teaching skills or teaching style are often popular among audience. The instructor of Positive Psychology, Tal Ben Shahar, is a psychology lecturer of Harvard University, whose courses Positive Psychology and Leader Psychology have been voted as the first and the third most welcomed courses respectively. Enjoying a good reputation among students, Doctor Tal, respected and admired by his students, is also titled with "the most welcomed lecturer" and "the mentor of life". When you learned his video, you may find why he is popular.

Doctor Tal is often very humorous in his class, "...But, there is a very big ' but' here...the head of my $\mathrm{PhD}$ programs actually estimated the average academic journal article is read by seven people...you know... and that includes the author's mother...(laughter)". This is a typical cold jest, with which Doctor Tal is familiar. Translating "you know" into “你说......" and combining it with next sentence
“这其中还包括作者的母亲”, the translator grasps Doctor Tal’ s tone accurately and expresses it vividly.

But as a professor, Doctor Tal is also very cautious in his lectures. In lecture 15 Perfectionism, Doctor Tal explains the meaning of "incapacitating”. "...note the word incapacitating, it is ...again, an incapacitating fear..." In this definition, Tal uses the word "note" and "again" to emphasize the accurate definition of incapacitating. If we translate them into “提到” and “再说一次”, the target audience may ignore the definition. However, translators give the final version like “注意” and “再强调一次”. This time, the audience may notice the importance of the definition. Such kind of version also shows the instructor's cautious attitude to the academic work

Different instructors have different teaching styles. For instance, instructors like Doctor Tal are good at adding some funny thing in their lecture; some instructors are good at telling abstruse theory in a digestible way. The second type of instructors often appeared in natural science courses. When translating their courses, translators should concentrate more on the academic terms' meaning and try to express their metaphor in a proper way. Above all, translators should change their translations strategies according to the instructor's teaching style.

\section{Simplifying the Sophisticated Principles}

For many students, the lack of expertise knowledge in particular area is a big problem. When they come into a new area, they are often restricted by some sophisticated principles [2]. In terms of this, translators should translate the source text in a simple way. Take the course Optimism for example, doctor Tal mentioned that the social psychology essentially started with some very important experiments, and he also analyzes the Milgrim effect(or obedience to authority) and the Zimbardo's prison experiment. The Milgrim effect is a famous experiment in psychology, but the mode of experiment is very complicate. People without background information of psychology cannot understand this term. In order to help the audience get the meaning in a short time, translators choose the key words of this experiment and explain the experiment into “权利服从研究”. In this way, people can get the result of the experiment clearly and will not be confined to the content of the experiment. Simplifying the sophisticated principles is an useful way in helping students to gain professional knowledge.

\section{Adding Proper Creative Words}

When the author mentions creative words, it is a general conception of humorous words, cyberwords (not computerused terms) and other kind of new words. The author proposed this strategy in consideration of students' characteristics. As the author mentioned above, at a relatively young age, students are curious about new things and willing to accept new things. Using proper creative words can raise their interests about the course and help them learn more things from the courses.

There is a sentence in lesson one, " ... "more outgoing, more cheerful, less introverted, more extroverted', and on 
and on, but here is the best one. So this is one of the local..." In the middle part of this sentence, "but here is the best one", under the context, no one would translated it into "最好的次”, but many people may translate it into “最重要的一次” or “最严重的一次”. It is a right version, but in the video, the translator uses the word “绝” to translate "the best one” as “最绝的一次”. The author thinks this is a perfect version. The word describes the instructors' situation accurately and successfully arouses audience's curiosity.

Another example in lesson 23, a student read a letter from an audience. In the letter, the audience expresses his thanks to doctor Tal. Here is the original sentence, “....and I didn't get the guts to do it until this year, thank you Tal, for helping me to get over my procrastination...". In the version, the last word "procrastination" was translated into “拖延症”, which is very accurate. But if the version was given in recent time, “懒癌” is also a good translation for "procrastination". “懒癌” is a new word on internet, an exaggerated description for lazy person. Using such cyber words may attract more students. In STNOER, accuracy should be put in the first place, in terms of this principle, translator can use some proper fashionable or humorous words to arouse audiences' interests, which will help the courses more welcomed.

\section{E. Highlighting the Rhetorical Function}

Many self-learners are attracted by the funny expression in the courses. However, in the process of the STNOER, "the rhetorical functions are ignored by some subtitle translators to some degree, resulting in the ineffective expression of rhetorical features, connotations and atmosphere of the original texts" [15]. In lesson 23, doctor Tal uses some words to contrast to his own course, " '.. so there are five things you need to be happy, the three things to be the great leader, the one secret of success, happiness and a perfect love life, over promising, under-delivering ...". Contrast and irony are obviously applied in the paragraph, so in the process of the subtitle translation, the translator should try to keep the same atmosphere. "over promising, under-delivering " means “言 过其实，无法兑现”, in order to express the exaggeration, the translator uses another version “夸大其词, 效果甚微”. From this version, audience can easily read between lines.

In lecture 4, the instructor uses repetition in the paragraph, "...just imagine the kind of life that you can experience, the kind of life you can lead...". The instructor uses repetition to emphasize his good wishes to the audience and the translator also use repetition in the version. “想象你将体验怎样的生活, 你 将拥有怎样的生活...”, with this version, the target audience can also feel the good wishes expressed by the instructor.

\section{F. Delivering Messages Directly}

Self-learners with outside world pressure are eager to learn some practical skills or useful information from the NOER, thus the version should be as direct as possible. In a speech, the instructor may use many modifiers to make it more interesting. Translators should select the key words in their speech and deliver them to the target audience. In the lecture 15, doctor Tal mentions the word "incapacitating", "...But an incapacitating failure is the failure that is debilitating us, that stops us, that prevents us from coping, from trying, from putting ourselves on the line...". Doctor Tal uses a lot of adjective in the sentence and he wants to express the definition of incapacitating with these words. If we translate the sentence word by word, then the version will be a tedious one. “.......但失能性畏惧是一种会让我们失去能力, 会 让我们停下脚步, 会阻止我们继续下去.......”, from this version, the target audience may still confuse about the word "incapacitating". The translators of the NetEase translate it into “.......但对失败的失能性畏惧是一种让我们在面对问题的时候裹 足不前的畏惧”. With this version, the audience can easily understand the word and the meaning of "incapacitating" is fully expressed.

Another sample in this lesson, "...how they want to get from where they are now to where they want to get to...". It seems a very long sentence; in fact, the instructor just wants to express "how to get to the end from the beginning". In the sentence, "where they are now" is the place you start and "where they want to get to" is the end. So the translators gave a translation like “怎么从起点到终点”, a short but perfect one. Delivering information directly can help those selflearners save time and learn more effectively.

\section{CONCLUSION}

As discussed above, by adopting the skopos theory and its specific translation methods, this thesis has analyzed the characteristics of network open educational resources' target audience and proposed specific translation strategy to different groups of target audience. The author chooses the Harvard Open Courses Positive Psychology for case study. Each example is analyzed in details, and the author also analyzes how these versions satisfy target audience's need.

Based on the analysis, the thesis finds that different groups of target audience have different necessities. Some professors pay more attention to the instructor's teaching skills and concepts, other professors are attracted by the instructors' personal characters. For this group of audience, translators need to use more academic and technical words in the version. As for student group, their main purpose is to learn something new, so translators can add some creative words in their version which may satisfy the student. The self-learners choose network open educational resources are often out of interest or forced by their job demand, so the translators need to highlight the rhetorical function and deliver the messages directly.

As the E-C subtitle translation research is limited abroad, the author has encountered lots of difficulties in collecting relevant foreign research papers and supporting materials. Translation strategies proposed by author still need further test. The theoretical backing is very powerful, but the argumentation is not very adequate and sufficient. Further studies remain to be made to perfect the translation strategies.

\section{REFERENCES}

[1] Chen Xiaoli, Qian Chuan. A Contrastive Study of Subtitle Translation of Online Publications at Yale University - A Case Study of the 
Translation Works of Ocourse and TFL Subtitle Groups [J]. Journal of Foreign Languages, 2013 (3): 100-103.

[2] Chen Hui, Wu Xiaoyu. An Analysis of Subtitling Translation of Online Open Courses - A Case Study of Modern British History [J]. Foreign Language Studies, 2013 (3): 183-197.

[3] Nord, C. Translating As A Purposeful Activity: Functionalist Approaches Explained[M]. Shanghai: Shanghai Foreign Language Education Press, 2001.

[4] Hermans, T. Translation in Systems: Descriptive and System-oriented Approaches Explained[M]. Shanghai: Shanghai Foreign Language Education Press, 2004.

[5] Nida, E A. Language and Culture-Contexts in Translating[M]. Shanghai: Shanghai Foreign Language Education Press, 2001.

[6] Peter, N. A Textbook of Translation[M]. Shanghai: Shanghai Foreign Language Education Press, 2002.

[7] Toury, G. Descriptive Translation Studies and Beyond[M]. Shanghai: Shanghai Foreign Language Education Press, 2001.

[8] Sperber, D.\& Wilson, D. Relevance: Communication and Cognition[M]. Shanghai: Shanghai Foreign Language Education Press, 2001.

[9] Bassnett Susan. Translation Studies [M]. Shanghai: Shanghai Foreign Language Education Press, 2004.

[10] Zhang Jinlan. Skopos Theory and Translation Methods [J]. Chinese Science and Technology Translation, 2014 (1): 35-38.

[11] Wu Qiongjun. A study on the method of network open courses subtitle translation, a case study of the "Justice" [J]. Journal of China Three Gorges University, 2014

[12] Wu Qiongjun. Features and methods of Network open courses' subtitle translation [J]. English Square, 2013 (12): 87-88.

[13] Feng Yuanyuan, Zhang Wujiang. Network open courses subtitle translation strategies [J]. Journal of Shenyang Institute of Technology, 2014 (2): 230-233.

[14] Li Yunxing. Subtitle translation strategy [J]. Chinese Translator, 2001 (7): 38-40.

[15] Shen Dawei. A Study of Subtitling Translation of Western Open Web Courses from the Perspective of Rhetoric - A Case Study of "Happiness Courses" and "Equity Courses" at Harvard University [D]. South China University of Technology, 2014. 